dosage employed here apparently had a slight sedative effect and reduced exploratory behavior (Marriott \& Spencer, 1965).

\section{REFERENCES}

CANDL AND, D. K., \& CAMPBELL, B. A Development of fear in the rat as measured by behavior in the open field. Journal of Comparative \& Physiological Psy chology, 1962, 55, 593-596.

DAVIDSON, P. W., \& WALK, R. D Differential visual depth discrimination of hooded as compared to albino rats Psychonomic Science, 1969, 14, 207-208.

DeHARDT, D. C. Visual cliff behavior of rats as a function of pattern size. Psychonomic Science, 1969, 15, 286-287.

HALL, C. S. Emotional behavior in the rat: I. Defecation and urination as measure of individual differences in emotionality. Journal of Comparative Psychology, $1934,18,385-403$.

HEBB, D. O. Drives and the C.N.S (conceptual nervous system) Psychological Review, 1955, 62, 243-254.

INNES, I. R., \& NICKERSON, M. Drugs acting on post ganglionic adrenergic nerve endings and structures innervated by them (sympathomimetic drugs). In L. S. Goodman and A. Gillman (Eds.), The pharmacological basis of therapeutics. New York: Crowell-Collier \& Macmillan, 1965. Pp. 486-496.

JARVIK, M. E. Drugs used in the treatment of psychiatric disorders. In L. S. Goodman and A. Gillman (Eds.). The pharmacological basis of therapeutics. New York: Crowell-Collier \& Macmillan, 1965. Pp. 162-178.

LATANE, B., \& SCHACTER, S. Adrenalin and avoidance learning. Journal of Comparative \& Physiological Psy chology, 1962, 55, 369-372.

LORE, R., \& SAWATSKI, D. Performance of binoeular and monoculax infant rats on the visual cliff. Journal of Comparative \& Physiological Psychology, 1969, 67, 177-181.

MALMO, R. B. Activation: A neuropsychological dimension. Psychological Review, 1959, 66, 367-386.

M A N T O, P. G. Blockade of epinephrine-induced decrement in activity by scopolamine. Psychonomic Science, 1967, 7, 203-204.

MARRIOTT, A. S., \& SPENCER, P. J. S. Effects of centrally acting drugs on exploratory behavior in rats. British Journal of Pharmacology, 1965, 24, 432-441.

MUNN, N. L. Handbook of psychological research on the rat. Boston: Houghton-Mifflin, 1950.

O'SULLIVAN, D. J., \& SPEAR, N. E. Comparison of hooded and albino rats on the visual cliff. Psychonomic Science, 1964, 1, 87-88.

ROUTTENBERG, A., \& GLICKMAN, S. E. Visual cliff behavior in albino and hooded rats. Journal of Comparative \& Physiological Psychology, 1964a, 58, 140-142.

ROUTTENBERG, A., \& GLICKMAN, S. E. Visual cliff behavior in undomesticated rodents, land and aquatic turtles, and cats (panthera). Journal of Comparative \& Physiological Psychology, 1964b、58, 143-146.

SCHACTER, S. \& SING ER, J. E. Cognitive, social and psysiological determinants of emotional state. Psychological Review, 1962, 69, 379-399.

SCHACTER S. \& WHEELER, L Epinephrine, chlorpromazine, and amusement. Journal of Abnormal \& Social Psychology, 1962, 65, 121-128.
SINGER, J. E. Sympathetic activation, drugs and fear. Journal of Comparative \& Physiological Psychology, 1963, 56. 612-615.

WALK, R. D., \& GIBSON, E. F. A comparative and analytical study of visual depth perception. Psychological Monographs, 1961, 75, Whole No. 519.
WALK, R. D. The study of visual depth and distance perception in animals. In $D$. $S$. Lehrman, $R$ A Hinde and E. Shaw (Eds.), Advances in the study of behavior. Vol. 1. New York: Academic Press, 1965. Pp. 99-154.

WINER, B. J. Statistical principles in experimental design. New York: McGraw-Hill, 1962.

\title{
D-amphetamine and palatability of a saccharin solution*
}

\author{
ELLEN R. BAUER and E. VICAR REYNOLDS III† \\ The College of William and Mary, Williamsburg, Va. 23185
}

Twenty-four female albino rats were assigned randomly to receive a 7 -day series of $3.0-\mathrm{mg} / \mathrm{kg}$ injections of either d-amphetamine sulfate in isotonic saline or saline IP. Half of each group drank .13\% sodium saccharin solution, the other half water. Fluid intakes were analyzed as intake per unit body weight. No differences were found among groups prior to drug administration. The prediction that $d$-amphetamine would produce a more taste-conscious animal was not substantiated. D-amphetamine produced a decrease in saccharin intake and an increase in water intake relative to saline controls.

Animals with medial hypothalamic (VMH) or lateral hypothalamic (LHA) damage show a change in preference behavior, such that their intake of foodstuffs and fluids seems highly dependent upon hedonic value (Teitelbaum, 1955; Nachman, 1967; Teitelbaum \& Epstein, 1962). D-amphetamine sulfate has been suggested to have its well-known anorexic effect either through increasing the electrical activity of the VMH (Grossman, 1967; Rosen, 1968) or through direct influence on LHA (Goodman \& Gilman, 1965, p. 502). In either case, causing an upset in the balance between these regulatory "centers" produces an animal that behaviorally appears satiated.

* This research was supported in part by a Grant-In-Aid to Research awarded by the Alumni Society of the College of William and Mary to the first author. The authors are indebted to Miss Winifred L. Angelo for her assistance.

†Now at the Department of Psychology. University of Georgia, Athens, Georgia.
According to a common sense approach to the regulation of intake, an animal that behaviorally appears satiated should be more highly sensitive to taste factors than if sated (Angelo \& Bauer, 1970). According to this reasoning, an animal injected with d-amphetamine ought to appear behaviorally satiated and, therefore, show less depression of drinking when a highly palatable fluid (.13\% sodium saccharin) is presented than when the fluid presented is water. This experiment was designed to test this prediction.

\section{METHOD}

The Ss were 24 female albino DUB/SDD rats (Flow Laboratories), approximately 100 days of age at the onset of the experiment. Half of the Ss were assigned randomly to the d-amphetamine sulfate 1 group $(1.0 \mathrm{cc} / \mathrm{kg}$ body weight of $3.0 \mathrm{mg} / \mathrm{cc}$ in a .9\% saline solution IP) and half to a physiological saline injection control group $(1.0 \mathrm{cc} / \mathrm{kg}$ body weight of the $.9 \%$ saline solution IP). Each of these 


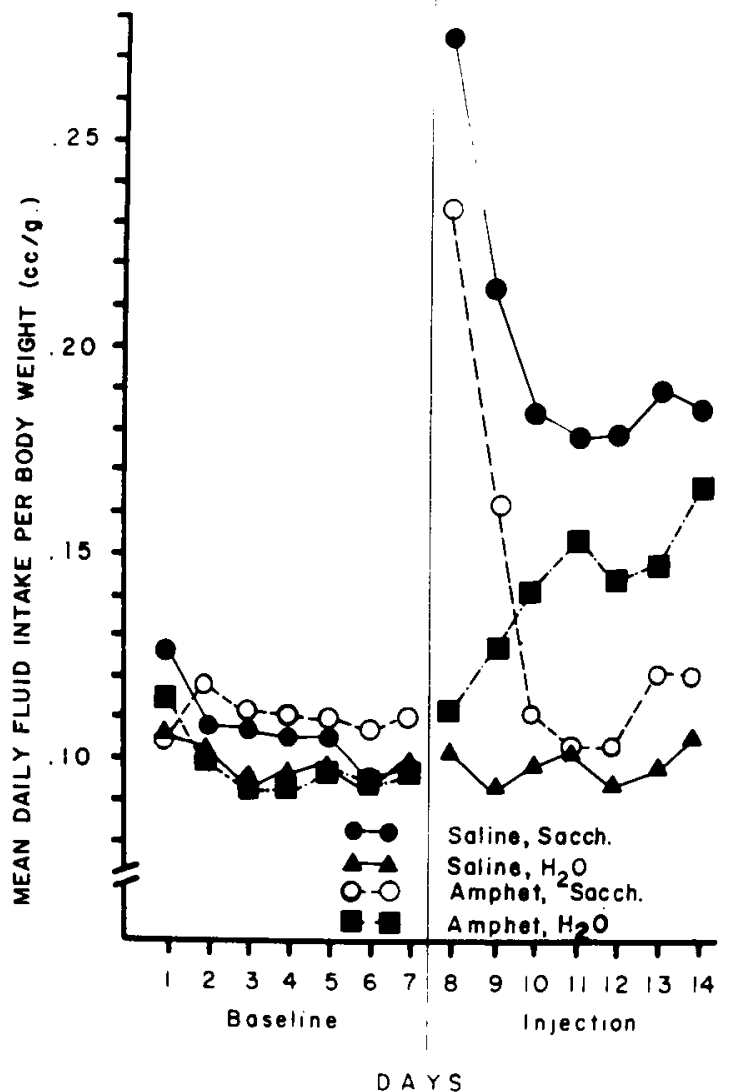

Fig. 1. Average daily relative fluid intake for both baseline and injection days, both for animals given saccharin during injection days and for those given water during injection days.

groups was further subdivided such that half received $.13 \%$ sodium saccharin on the injection days and the rest received water. All Ss were maintained under ad lib food (Purina Laboratory Chow meal) and fluid. They were housed in standard rat metabolism cage units (Acme Metal Products). Daily records were made only of fluid intake and body weight. Animals were maintained under 24 -h light conditions.

Thus, the design of the experiment involved four groups of six rats each. All animals were allowed 7 days to adapt to living in the metabolism cage (baseline period). On the eighth day of the experiment the injections (amphetamine or saline) were begun, as was the presentation of differential fluids (saccharin or water). The testing period lasted 7 days.

\section{RESULTS}

Because there was great variability in the weights of the animals, the fluid intakes were analyzed as a ratio of daily fluid intake (cc) to daily body weight (grams). These data are presented in Fig. 1. The baseline and injection days data were analyzed separately. Each analysis was a 2 by 2 by 7 analysis of variance with repeated measures on the last factor (days). Analysis of the baseline water data yielded a significant $F$ only for the days factor $(F=2.24, \mathrm{df}=6 / 120)$. Thus, daily water intake was not significantly different for the four groups prior to the introduction of the experimental manipulations.

The critical data are the relative fluid intake data on injection days, presented in Fig. 1. The analysis of variance performed on these data yielded a significant effect of the fluid (saccharin or water) presented $(F=5.33, d f=1 / 20)$ and a significant Drug by Fluid interaction $(F=6.88$, $\mathrm{df}=1 / 20$ ). Thus, as predicted, the drug effect significantly interacted with the changing of the fluid palatability. However, the direction of the interaction is the reverse of that predicted. From Fig. 1 it is apparent that injecting saline into animals who are drinking water does nothing to their intake. On the other hand, injecting amphetamine into animals who are drinking water caused a large increase in relative daily water intake over days. This increased intake over days as a result of the drug is contrary to other findings (e.g., Falk \& Burnidge, 1970). This difference in findings could be a consequence of methodological differences. Most experiments using amphetamines use a "one-shot" or spaced injection approach rather than a continuous series of injections.

The saccharin-d rinking amphetamine-injected Ss show a normal shaped ad lib saccharin intake curve (e.g., Bauer, 1969) for the first few days, although their total intake on any day is less than that of the saline-injected saccharin animals. Toward the end of the injection period, however, the saccharin amphetamine-injected animals begin to increase their intake in a fashion similar to the increases shown by the amphetamine-water group.

The results are the opposite of those originally predicted. Injections of d-amphetamine depressed relative fluid intake of animals drinking saccharin below the level of those drinking saccharin bt injected with saline. On the other hand, injections of $d$-amphetamine increased the intake of animals drinking water above the level of those drinking water but injected with saline. Thus, d-amphetamine, when given to ad lib animals drinking a highly palatable saccharin solution, produced a lessened daily intake, whereas, when given to ad lib animals drinking a supposedly "neutral" solution (water), it produced an increased daily intake. However, the intake of the palatable fluid by the d-amphetamine animals generally was higher than that of saline-injected animals drinking water.

\section{REFERENCES}

ANGELO, W. L. \& BAUER E R Decreased quinine tolerance as a function of water deprivation. Paper presented at the meeting of the Virginia Academy of Science, Richmond, May 1970.

BAUER, E $R$. Deprivation changes initial affective value of sodium saccharin. Psychonomic Science, 1969, 16, 275.

FALK, J. L., \& BURNIDGE, G. K. Drug antagonism and water intake. Physiology \& Behavior, 1970, 5, 193-198.

GOODMAN, L. S., \& GILMAN, A. The pharmacological basis of therapeutics. (3rd ed.) New York: Macmillan, 1965.

GROSSMAN, S. P. A textbook of physiological psychology. New York: Wiley, 1967.

NACHMAN, M. Hypothalamic hyperphagia, finickiness and taste preferences in rats. Proceedings, 75th Annual Convention, APA, 1967, 127-128.

ROSEN, E. F. Amygdaloid complex and medial hypothalamic nucleus in the regulation of food. (Doctoral dissertation, University of Illinois.) Ann Arbor, Mich: University Microfilms, 1968, No.68-12, 189.

TEITELBAUM，P. Sensory control of hypothalamic hyperphagia. Journal of Comparative \& Physiological Psychology, $1955,48,156-163$.

TEITELBAUM, $P$ \& EPSTEIN, A. $N$ The lateral hypothalamic syndrome: Recovery of feeding and drinking after lateral hypothalamic lesions. Psychological Review, 1962, 69, 74-90.

$$
\text { NOTE }
$$

1. The d-amphetamine sulfate was generously supplied by Smith, Kline and French Labs., Philadelphia, Pa. 